Report

\title{
Multiple signaling pathways are activated during insulin-like growth factor-I (IGF-I) stimulated breast cancer cell migration
}

\author{
Xihong Zhang ${ }^{1}$, Min Lin $^{2}$, Kenneth L. van Golen ${ }^{2}$, Kiyoko Yoshioka ${ }^{3}$, Kazuyuki Itoh ${ }^{3}$, and \\ Douglas Yee ${ }^{1}$ \\ ${ }^{1}$ Department of Medicine, University of Minnesota Cancer Center, Minneapolis, MN, USA; ${ }^{2}$ Department of Internal \\ Medicine, University of Michigan, Ann Arbor, MI, USA, ${ }^{3}$ Laboratory of Tumor Biology, Osaka Medical Center for \\ Cancer, Osaka, Japan
}

Key words: breast neoplasms, cell motility, focal adhesion kinase, insulin-like growth factor-I, mitogen activated protein kinase, Rho, type I IGF receptor

\begin{abstract}
In order to display the full metastatic phenotype, the cancer cell must acquire the ability to migrate. In breast cancer, we have previously shown that insulin-like growth factor I (IGF-I) enhances cell motility in the highly metastatic MDA-231BO cell line by activating the type I IGF receptor (IGF1R). This motility response requires activation of IRS-2 and integrin ligation. In order to identify the key molecules downstream of IRS-2, we examined several signaling pathways known to be involved in cell motility. Focal adhesion kinase (FAK) was not activated by IGF-I, but IGF-I caused redistribution of FAK away from focal adhesion plaques. IGF-I treatment of MDA$231 \mathrm{BO}$ cells activated RhoA and inhibition of Rho-kinase (ROCK) inhibited the IGF-mediated motility response. The mitogen activated protein kinase (MAPK), p38, was also activated by IGF-I and inhibition of p38 by SB203580 blocked IGF-I induced cell motility. ROCK inhibition with Y-27632 also inhibited p38 phosphorylation suggesting that p38 lies downstream of ROCK. Both Erk1,2 and phosphatidyl-3 kinase (PI3K) were required for IGF-I stimulated cell motility, but only PI3K appeared to be directly downstream of IGF-I. Thus, IGF-I activation of its receptor coordinates multiple signaling pathways required for cell motility. Defining the key molecules downstream of the type I IGF receptor may provide a basis for optimizing therapies directed at this target.
\end{abstract}

\section{Introduction}

The ability of breast cancer to metastasize to distant organs leads to clinically incurable disease. The phenotypes associated with metastatic breast cancer cells are unregulated cell growth and survival, decreased cell-cell adhesion, increased ability to degrade the extracellular matrix, and increased cell motility. Cell motility changes are associated with cytoskeletal reorganization and the activation of multiple signaling pathways, which can be induced by growth factors. Insulin-like growth factor-I (IGF-I) has been shown to play important roles in enhancement of breast cancer cell motility [1, 2]. Multiple signaling pathways are activated downstream of the type I IGF receptor (IGF1R) and understanding how these specific pathways contribute to cell motility may be very important in the efforts to develop new therapeutic strategies for breast cancer.

The family of Rho GTPases comprises a group of signaling molecules that regulate a wide range of biological processes in cancer, including reorganization of cytoskeleton, cell-cycle control, apoptosis, tumorigenesis, adhesion, invasion, and metastasis [3, 4]. Rho proteins and their effectors are overexpressed in breast tumors and expression levels positively correlate with the progression of breast cancer [5-7]. RhoC GTPase is overexpressed in $90 \%$ of inflammatory breast cancer and positively correlates with the tumor metastatic potential $[8,9]$. In the rat, Rho family GTPases were found to regulate mammary epithelial cell growth and metastasis [10].

Rho-associated kinase (ROCK) is a major effector of RhoA and RhoC. Upon activation by Rho, ROCK inhibits myosin light chain (MLC) phosphatase and results in an increase in MLC phosphorylation and, consequently, increases myosin-based contractility [11]. ROCK also activates LIM-kinase (LIMK) and subsequently phosphorylates cofilin and results in the stabilization of actin filaments [12]. Both of these actions result in enhanced cell motility. Yoshioka et al. reported that the level and activity of endogenous LIMK1 is increased in invasive breast and prostate cancer cell lines and overexpression of LIMK1 in MCF-7 and in MDAMB-231 human breast cancer cell lines increased their motility [13]. Taken together, these studies suggest that Rho/ROCK signaling is involved in breast cancer biology and warrant further investigation. 
In other cell system, Rho family GTPases have also been reported to regulate p38-MAPK and JNK [14-16]. Erk and RhoA differentially regulate pseudopodia growth and retraction during $\mathrm{G}$ protein coupled receptor mediated chemotaxis [17]. ROCK signaling is involved in the collapse of the vimentin intermediate filament network, which may be an essential element in chemokine-induced transendothelial migration [18, 19]. Rho GTPases are required in an oncogenic IGF1R-induced NIH 3T3 cell transformation [20]. In Schwann cells, IGF-I regulates cell motility by reorganization of the actin cytoskeleton via the downstream activation of a PI3K, Rac and cdc42 small GTPases, and FAK pathway [21].

We have previously shown that IGF-I stimulates cell adhesion and motility in a metastatic breast cancer cell line, MDA-231BO, via a specific adaptor protein insulin receptor substrate-2 (IRS-2). In this cell line, decreasing levels of IRS-2 with an antisense construct will diminish IGF-mediated motility [2]. We have also shown in this cell system that IGF1R and integrin action are linked, as disruption of integrin binding to its receptor influences IGF-I signaling [22]. In this study, we further investigated the signals downstream and adjacent to IRS-2 activation in MDA-231BO cells. We found that IGF-I stimulated subcellular reorganization of IRS-2 and focal adhesion kinase (FAK) while also inducing cytoskeletal rearrangement. Along with these morphological changes, IGF-I stimulated RhoA activation and subsequently increased MLC phosphrylation. p38-MAPK was also activated downstream of Rho/ROCK signaling. Erk and PI-3K signaling pathway are also involved in the IGF-I induced cell migration.

\section{Materials and methods}

\section{Cells and reagents}

MDA-231BO breast cancer cell line, a bone seeking metastatic variant of MDA-MB-231 [23], was kindly provided by Dr. Toshiyuki Yoneda (University of Texas Health Science Center, San Antonio, TX). The culture media and fibronectin were purchased from Life Technologies, Inc. (Rockville, MD). IGF-I was purchased from Gro Pep (Adelaide, Australia). Rho assay kit and IRS-2 antibody were purchased from Upstate Biotechnology (Waltham, MA). Phospho-MLC antibody (used at 1:300 in immunoblotting) was kindly provided by Dr. James M. Staddon (University College London, UK) [24]. Horseradish peroxidase-conjugated RC-20 antiphosphotyrosine antibody was purchased from Transduction Labs (Lexington, KY). $\alpha 5$ inhibitory and $\beta 1$ stimulatory integrin antibodies were purchased from Chemicon (Temecula, CA). FAK and vimentin antibodies were purchased from Santa Cruz Biotechnology, Inc (Santa Cruz, CA). TRITC-labeled pholloidin, total MLC antibody and all other chemicals were purchased from Sigma (St. Louis, MO).

\section{Rho activation assay}

Total Rho (both GDP- and GTP-bound forms) assay was performed according to manufacturer's instruction (Upstate). Levels of GTP-bound active-RhoA, RhoB, RhoC and RhoG were measured by an activation assay as previously described [25, 26]. Briefly, GST-rhotekin (a gift from Dr. John Collard of the Netherlands Cancer Institute) was prepared fresh from a $50 \mathrm{ml}$ overnight bacterial culture, stimulated for $2 \mathrm{~h}$ with $0.1 \mathrm{mM}$ IPTG to induce GST-protein production. GST-rhotekin was bound to $50 \%$ slurry of glutathione-sephrose 4B (Amersham, Uppsala, Sweden). MDA-231BO cells were grown to $70 \%$ confluence, serum starved for $24 \mathrm{~h}$ in IMEM zinc option (Gibco, Gaithersburg, MD), trypsinized, washed and allowed to rest in suspension flasks (Griener Bio-one, ISC Bioexpress, Kaysville, UT). Cells were stimulated with $5 \mathrm{nM}$ IGF-I and $10 \times 10^{6}$ cells/ time point were lysed with ice-cold GST-Fish buffer $(10 \%$ Glycerol, $50 \mathrm{mM}$ Tris $\mathrm{pH} 7.4,100 \mathrm{mM} \mathrm{NaCl}$, $2 \mathrm{mM} \mathrm{MgCl}, 1 \% \mathrm{NP}-40$ ) at $0,1,3,10$ and $30 \mathrm{~min}$. Protein lysates, $900 \mu \mathrm{l}$ of $1 \mu \mathrm{g} / \mu \mathrm{l}$, were precleared with glutathione-sepharose $4 \mathrm{~B}$ for $1 \mathrm{~h}$ at room temperature. The cleared lysates were incubated with GST-rhotekinsephrose conjugate at $4{ }^{\circ} \mathrm{C}$ for $30 \mathrm{~min}$. The agarose conjugate was washed three times in GST-Fish buffer, collected by centrifugation, resuspended in Laemelli buffer, separated by SDS-PAGE on an $8-20 \%$ Tris- $\mathrm{HCl}$ gradient gel (BioRad, Hercules, CA), transferred to nitrocellulose and probed with either RhoA, RhoB, RhoC and RhoG antibodies (Santa Cruz Biotechnology, Santa Cruz, CA). Total (GTP- and GDP-bound) RhoA, RhoB, RhoC and RhoG levels were measured at each time point by Western blot analysis. Aliquots of $30 \mu \mathrm{g}$ protein lysate were separated by SDS-PAGE, transferred to nitrocellulose and probed with corresponding antibodies (Santa Cruz Biotechnology). Each analysis was performed in triplicate.

\section{Cell motility assay}

Cell motility was measured in a 10 well chamber as previously described [2]. About $0.4 \mathrm{ml}$ SFM with or without IGF $(5 \mathrm{nM})$ was placed in the bottom wells of the chamber. A polycarbonate polyvinylpyrrolidone free filter ( $12 \mu \mathrm{m}$ pore size) was placed above this. Cells were detached in PBS-EDTA and then were resuspended in SFM. $0.3 \mathrm{ml}$ cell suspension $\left(5 \times 10^{5}\right.$ cells $\left./ \mathrm{ml}\right)$ was added to the top well chamber above the filter. For the inhibitor assays, cells were pretreated with inhibitors for $30 \mathrm{~min}$ at $37^{\circ} \mathrm{C}$ before they were added to the top wells. The chamber was then incubated for $6 \mathrm{~h}$ at $37^{\circ} \mathrm{C}$. At the end of the incubation, cells remaining on the topside of the filter were scraped off with cotton swabs. The filter was then removed from the chamber and the cells that had migrated to the underside of the filter were fixed and stained in HEMA3. The filter was mounted on a glass microscope slide and cells were counted in 10 different areas with the aid of a light microscope. 
Cell motility was also measured by gold particle migration assay [27, 28]. Briefly, hot gold solution (22 part of $\mathrm{H}_{2} \mathrm{O}, 12$ part of $36.5 \mathrm{mM}$ sodium carbonate, 3.6 part of $14.5 \mathrm{mM}$ gold chloride and 3.6 part of $0.1 \%$ formaldehyde) was poured onto fibronectin coated glass coverslips. Gold particles were allowed to precipitated overnight at $4{ }^{\circ} \mathrm{C}$. Then the supernatant was discarded and $2 \times 10^{4}$ cells were seeded on the gold particle coated coverslips and allowed to adhere to the coverslip for about $2 \mathrm{~h}$ before adding different treatments. Cells were allowed to migrate for another $6 \mathrm{~h}$ and fixed with 3.5\% glutaraldehyde for $20 \mathrm{~min}$ and then the coverslips were mounted with Permount. During the migration, cells cleared up their pass, and the images were acquired using a Spot 2 digital CCD on a Nikon E-1000 microscope at $[1 \mathrm{x}]$ and ImagePro Plus (Media Cybernetics Inc., Silver Spring, MD) was used to quantify the cleared areas.

\section{Cell lysate preparation}

Stimulation experiments were performed as previously described. Briefly, cells were cultured in Dulbecco's Modification of Eagle's Medium (DMEM, Cellgro, Herndon, VA) with $10 \%$ fetal calf serum (Summit Biotech, Fort Collins, CO) and $10 \mathrm{nM}$ insulin until 70\% confluent, then washed twice with phosphate buffered saline (PBS, Biofluids, Rockville, MD). Medium was then changed to SFM for $24 \mathrm{~h}$, then replaced with SFM plus $5 \mathrm{nM}$ IGF-I for $10 \mathrm{~min}$. Cells were washed twice in ice cold PBS and lysed with $500 \mu \mathrm{l}$ per $10 \mathrm{~cm}$ plate with TNESV buffer (50 mM- Tris-pH 7.4, 1\% NP-40, $2 \mathrm{mM}$ EDTA, $100 \mathrm{mM} \mathrm{NaCl}, 10 \mathrm{mM}$ sodium orthovanadate, $1 \mathrm{mM}$ phenylmethylsulfonylfluoride, $20 \mu \mathrm{g} / \mathrm{ml}$ leupeptin, $20 \mu \mathrm{g} / \mathrm{ml}$ aprotinin). Protein concentration of the cleared lysates was determined by the copper-bicinchoninic acid method with a Pierce Laboratory kit (Rockford, IL).

\section{Immunoprecipitation}

All steps were performed on a platform rocker at $4{ }^{\circ} \mathrm{C}$. Equal amounts of protein $(500 \mu \mathrm{g})$ were first pre-cleared with $25 \mu$ of protein A agarose (Pierce, Rockford, IL) for $30 \mathrm{~min}$, then incubated with the FAK antibody overnight at concentrations according to the manufacturer's instructions. $25 \mu \mathrm{l}$ of protein A agarose was then added for $2 \mathrm{~h}$, followed by three washes with TNESV buffer. Beads were resuspended in $2 \times$ Laemmli loading buffer with $30 \mathrm{mg} / \mathrm{ml}$ dithiothreitol, boiled and separated by SDS-PAGE.

\section{Immunoblotting}

After SDS-PAGE proteins were transferred overnight to nitrocellulose membranes (Bio Rad, Hercules, CA). All blotting steps were carried out at room temperature with gentle rocking. The membranes were blocked in $5 \%$ non-fat dry milk in Tris-buffered saline -Tween 20 (TBST: $0.15 \mathrm{M} \mathrm{CaCl}$, 0.01 M Tris HCl- PH 7.4, 0.05\% Tween 20). For antiphosphotyrosine blotting with RC20 , membranes were washed five times over $30 \mathrm{~min}$ with TBST after blocking, incubated with a 1000:1 dilution in TBST for $2 \mathrm{~h}$, washed, then chemilumiescence was performed as described below. The other blottings were performed with $1 \mathrm{~h}$ incubation in primary antibody, blots were then washed and incubated with a 2000:1 dilution of HRP linked anti-rabbit secondary antibody in blocking buffer for $1 \mathrm{~h}$, followed by further washing. Enhanced chemiluminescence was performed according to manufacturer's instructions (Pierce, Rockford, IL).

\section{Cell adhesion assay}

Cell attachment was assayed in a 24 well tissue culture plate. The wells were first coated with $0.2 \mathrm{ml}$ of $10 \mu \mathrm{g} / \mathrm{ml}$ fibronectin overnight at $4{ }^{\circ} \mathrm{C}$. Wells were then washed twice with PBS. Serum-starved cells $\left(1 \times 10^{6} / \mathrm{ml}\right)$ in $0.5 \mathrm{ml} \mathrm{SFM}$ plus/minus $5 \mathrm{nM}$ IGF-I in the presence or absence of $2 \mu \mathrm{M}$ ROCK inhibitor Y-27632 were added to the wells. After incubated for $45 \mathrm{~min}$ at $37^{\circ} \mathrm{C}$, the plate was rinsed three times with PBS to wash away the non-attached cells. The attached cells were then fixed onto the well with $20 \%$ methanol for $10 \mathrm{~min}$ at room temperature. The fixed cells were stained with $0.5 \%$ crystal violet in $20 \%$ methanol for $5 \mathrm{~min}$ and then rinsed with water and air dried for $15 \mathrm{~min}$. The crystal violet contained cells were solubilized with $100 \mu \mathrm{l}$ of $0.1 \mathrm{~N}$ sodium citrate in $50 \%$ ethanol and transferred to 96 well assay plate and read O.D. at $570 \mathrm{~nm}$. The numbers of attached cells were proportional to the number of O.D. reading.

\section{Confocal microscopy}

To examine the expression and localization of IRS-2, FAK and reorganization of F-actin and vimentin, we performed confocal microscopy. MDA-231BO cells were grown on fibronectin coated glass coverslips in the presence of serum. After $24 \mathrm{~h}$, cells were washed and placed in SFM overnight. For immunofluorescent visualization of IRS-2, FAK and vimentin, cells were fixed with cold methanol for $20 \mathrm{~min}$ after treatment (plus and minus $5 \mathrm{nM}$ IGF) over several time points. The fixed samples were then permeabilized with $0.1 \%$ Triton X-100 in PBS for $20 \mathrm{~min}$ at room temperature. After being washed three times with PBS and blocked with $1 \%$ bovine serum albumin for $30 \mathrm{~min}$, samples were subjected to fluorescence staining by using unlabeled IRS-2, FAK and vimentin primary antibodies and FITC-labeled secondary antibodies for $1 \mathrm{~h}$ each at room temperature. Cells were examined with a Bio-Rad MRC-1024 confocal laser scanning microscope (Hercules, CA) with a $60 \times$ objective lens under oil immersion. F-actin was visualized by direct TRITCpholoidin binding to the fixed sample. 


\section{Results}

Alteration of subcellular localization IRS-2 and FAK and reorganization of $F$-actin and vimentin during IGF-mediated cell migration

We have previously shown that IGF-mediated cell motility was diminished when IRS-2 levels were decreased by anti-sense RNA [2], while phosphorylation of IRS-2 was only minimally affected. IGF1R and integrins cooperate in this process [22] and it was possible that IRS-2 molecules coordinated key signaling events involved in cell motility. To determine if IGF-I exposure influenced IRS-2 subcellular localization, we examined cells by immunofluorescent microscopy. In the unstimulated state, IRS-2 was primarily located in the cytoplasm (Figure 1, upper left panel), $60 \mathrm{~min}$ after IGF-I exposure IRS-2 could be found at the cell's leading edge. This result was also demonstrated in MCF-7 ATCC cells and it was specific to IGF-I treatment [29].

During cell migration, constant morphological changes occur. The regulation of morphological changes in eukaryotic cells is a complex process involving major reorganization of cytoskeleton components including actin microfilaments, microtubules and intermediate filaments. It has been reported that Rho activation is involved in the collapse of the vimentin intermediate filament network and in the polymerization of actin fibers [19]. Therefore, we investigated if F-actin and vimentin went through reorganization during IGF-I mediated cell migration. As shown in Figure 1 (upper right panel), in unstimulated cells actin staining was diffusely detected in the entire cell body. After IGF-I treatment, F-actin was bundled along the cell border. In contrast to actin, vimentin was bundled before IGF-I treatment and became less organized during IGF-I mediated cell migration (Figure 1, lower right panel). Thus, IGF-I treatment resulted in morphologic reorganization of the cytoskeleton required for the initiation of cell migration.

IGF-I has been shown to either positively or negatively modulate focal adhesion proteins involved in integrin signaling such as FAK, Cas, and paxillin. We examined the ability of IGF-I to stimulate FAK activation by immunoprecipitation followed by anti-phospho-tyrosine blotting (Figure 2). In cells attached to substrate, IGF-I treatment did not increase FAK phosphorylation. However, FAK localization after IGF-I treatment, was substantially altered (Figure 1, lower left panel). As cells start to spread and migrate after IGF-I exposure, FAK gradually disappeared from focal adhesion sites. Further, cells in suspension have very little FAK activation and attachment to fibronectin will stimulate its phosphorylation (Figure 2). Inhibitory $\alpha 5$ integrin antibody blocked this activation but stimulatory $\beta 1$ integrin antibody did not (Figure 2). These results suggest that FAK phosphorylation is mainly regulated by integrin signaling while subcellular localization of FAK was influenced by IGF-I treatment. Thus, IGF-I may play an important role in regulating focal adhesion contacts by coordinating FAK localization without activating its kinase activity.

\section{IGF-I stimulated Rho A activation in MDA-231BO cells in suspension}

The formation and remodeling of focal contacts and the cytoskeletal changes during cell movement are dynamic processes, which are under the regulation of protein tyrosine kinases and the Rho family of small GTPases. To determine if IGF-I stimulated Rho activation, we measured the GTP-bound (activated) and total Rho in MDA-231BO cells. As shown in Figure 3a, IGF-I rapidly stimulated Rho activation 2-fold within $3 \mathrm{~min}$ in
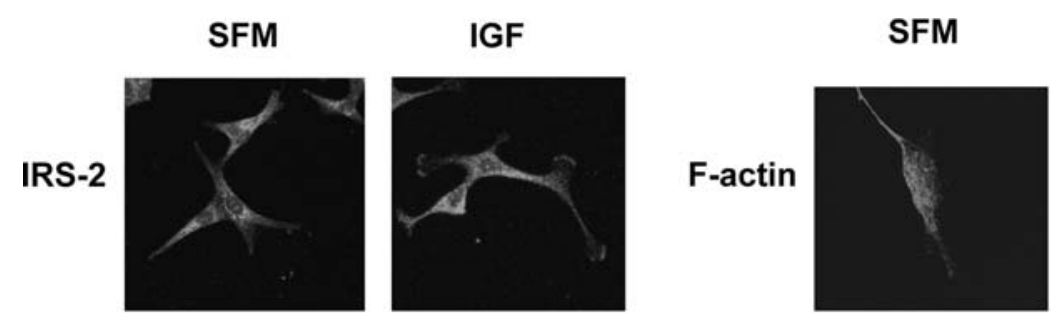

\section{IGF}
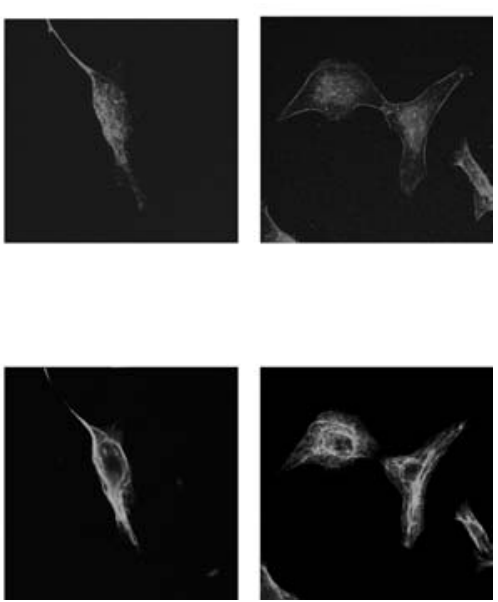

Figure 1. IRS-2 and FAK cellular locations were altered by IGF-I during cytoskeletal reorganization. Metastatic variant MDA-231 BO cells were grown on glass coverslips coated with fibronectin. Cells were incubated in media containing fetal bovine serum overnight, then cells were starved with SFM for $24 \mathrm{~h}$. Cells were then treated with or without $5 \mathrm{nM}$ IGF-I for $1 \mathrm{~h}$ and fixed and stained for IRS-2, FAK, F-actin and vimentin. 


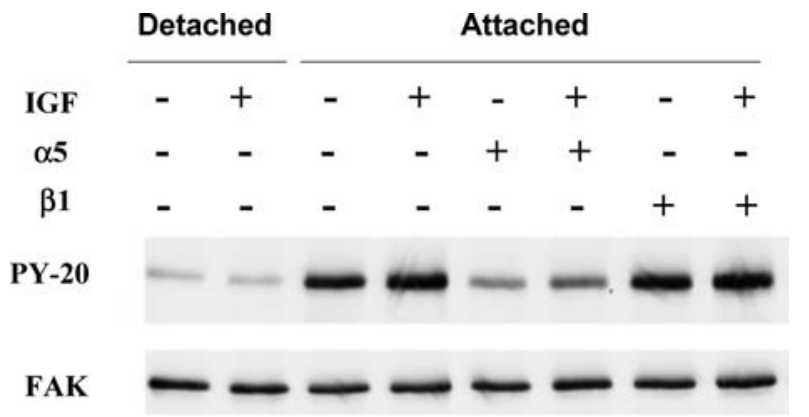

Figure 2. IGF-I did not affect FAK tyrosine phosphorylation. MDA$231 \mathrm{BO}$ cells were incubated for $30 \mathrm{~min}$ in the presence of $\alpha 5$ integrin inhibitory antibody, $\beta 1$ integrin stimulatory antibody or no additional antibody. After pre-incubation, cells were treated with or without $5 \mathrm{nM}$ IGF-I and allowed to attach to the fibronectin coated plate for $30 \mathrm{~min}$. Another set of cells was in suspension and treated with and without IGF for $30 \mathrm{~min}$. Cell lysates were immunoprecipitated with FAK antibody followed by anti-phospho- tyrosine blotting. Then the same blots were stripped and reblotted with FAK antibody. The experiment was repeated three times; a representative example is shown.

cells in suspension. In order to determine the species of Rho activated we further examined RhoA, RhoB, RhoC and RhoG activation by immunoprecipitation with specific antibodies. As shown in Figure 3b, RhoA was activated by IGF-I treatment within $1 \mathrm{~min}$. RhoB activation was decreased by IGF-I treatment, while RhoC and RhoG were unchanged (data not shown). IGF-I treatment had minimal effect on $\mathrm{Cdc4} 2$ activation while GTP-bound Rac1 was slightly increased. We also failed to detect IGF-I effect on RhoA activation in attached MDA-231BO cells (data not shown), suggesting the IGF-I stimulatory effect on Rho occurred in cells detached from extracellular matrix.

\author{
Rho-kinase (ROCK) inhibitor Y-27632 effectively \\ inhibited IGF-I mediated cell migration in MDA-231BO \\ cells, but not cell adhesion
}

ROCK is one of the best characterized downstream Rho effectors. Upon its activation, ROCK inhibits myosin light chain phosphatase to enhance phosphorylation of MLC, which has essential role in cell contractility. Several compounds have been developed to block ROCK, including Y-27632 [30]. To determine if ROCK acting downstream of RhoA had a role in IGF-mediated motility, we treated MDA-231BO cells with Y-27632 $(0.2-200 \mu \mathrm{M})$ prior to IGF-I exposure. As shown in Figure 4a, low concentrations of Y-27632 (less than $2 \mu \mathrm{M})$ effectively blocked IGF-I stimulated cell migration. Higher concentrations $(>2 \mu \mathrm{M})$ blocked both basal and IGF-stimulated cell migration. To examine MLC phosphorylation in response to IGF-I, we treated suspension cells with IGF-I in the presence or absence of $2 \mu \mathrm{M}$ Y-27632. Figure $4 \mathrm{~b}$ shows that IGF-I stimulated MLC phosphorylation while Y-27632 effectively blocked this activation.

In Boyden chamber assays, cell adhesion is a prerequisite of cell migration. We have previously shown that IGF-I enhances both motility and adhesion in MDA-231BO cells [2]. At concentrations shown to inhibit migration, Y-27632 had no effect on IGF-I stimulated adhesion to fibronectin (Figure 4c). To confirm that ROCK affected migration of cells already attached to the substrate, we used a gold particle migration assay, which allows cells to adhere prior to the measurement of motility. As shown in Figure 4d, $2 \mu \mathrm{M}$ Y-27632 inhibited IGF-I stimulated motility at a level similar to that observed in the Boyden chamber assay (Figure 4a). (b)

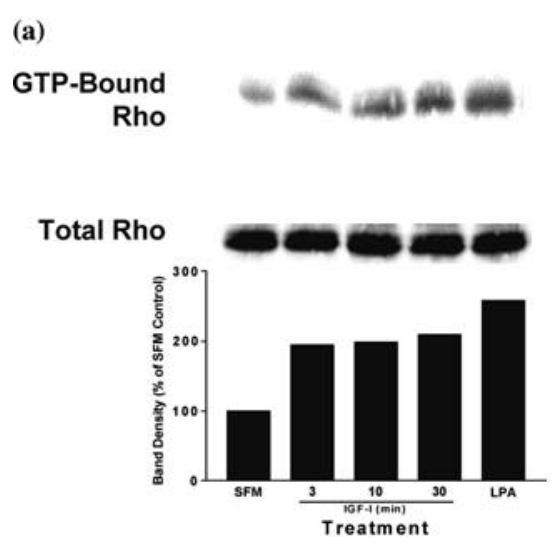

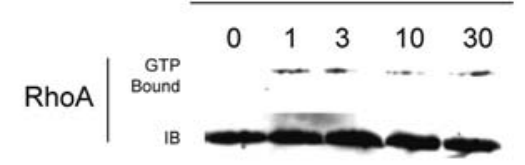

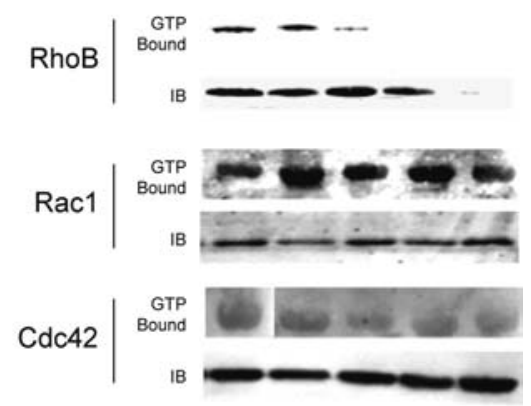

Figure 3. IGF-I stimulated Rho A activation in MDA-231BO breast cancer cells (a) MDA-231BO cells in suspension were examined for total Rho activation after treatment with $5 \mathrm{nM}$ IGF-I for 3,10 and $30 \mathrm{~min}$ by using the Rho assay kit as described in Materials and Methods. Treatment with lysophosphatidic acid (LPA) for 3 min was used as a positive control. The graph demonstrates the density of the bands and quantified as the ratio of activated Rho/total Rho (as internal control). The experiment was repeated three times; a representative example is shown. (b) MDA-231 BO cells in suspension were examined for RhoA, B, and Racl and cdc42 activation (GTP bound) after treatment with $5 \mathrm{nM}$ IGF-I for 3, 10 and $30 \mathrm{~min}$ as described in the methods. Total protein immunoblots blots for corresponding small GTPases (IB) were used as loading control. The experiment was repeated three times; a representative example is shown. 

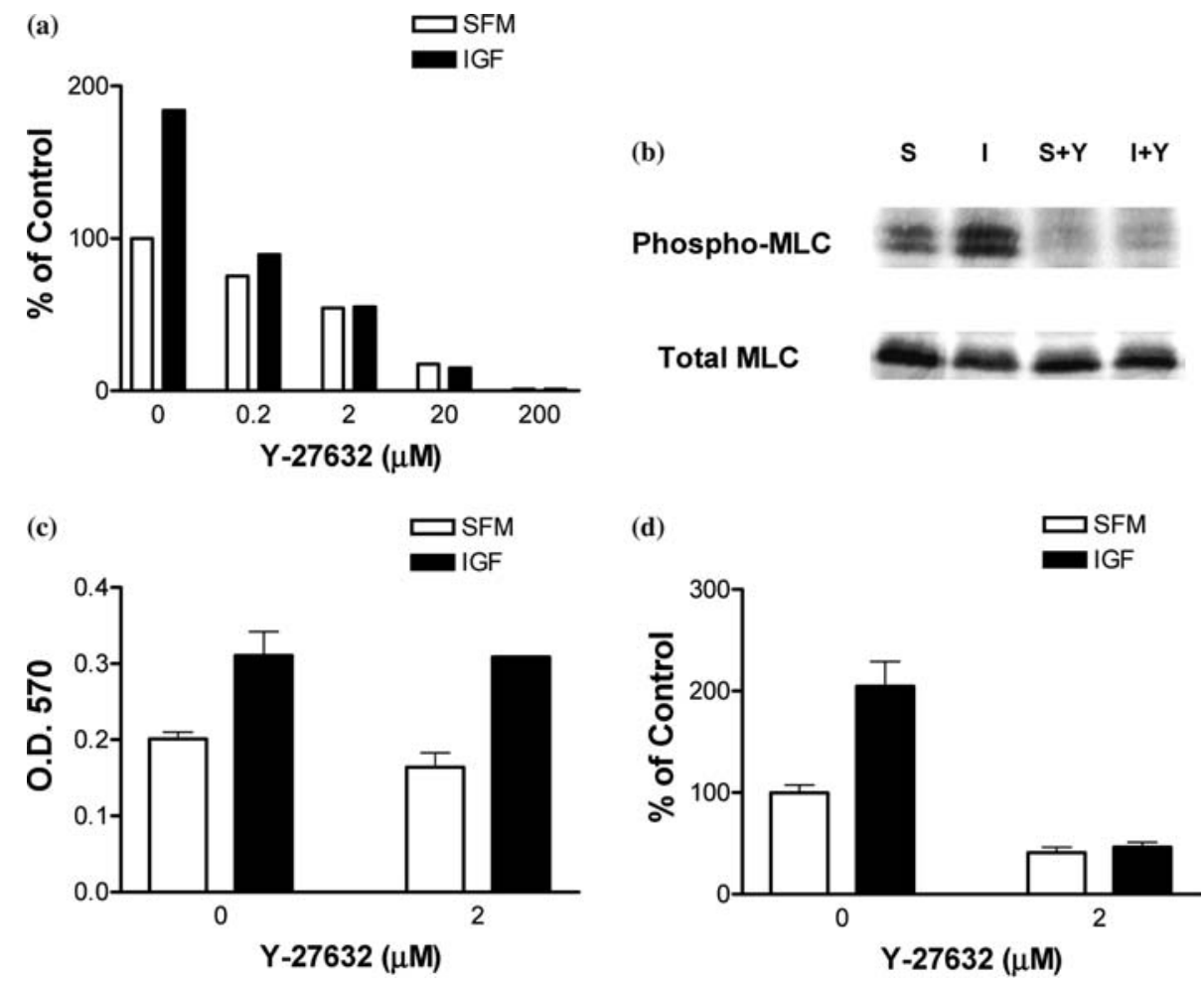

Figure 4. ROCK inhibitor Y-27632 blocked MLC phosphorylation and motility in MDA-231BO cells. (a) MDA-231BO cells were incubated in increasing concentrations $(0.2-200 \mu \mathrm{M})$ of ROCK inhibitor Y-27632. Cell motility was examined in both basal and $5 \mathrm{nM}$ IGF-I containing media using the modified Boyden chamber assay. Results are shown as percentage basal migration (without IGF-I and Y-27632). (b) Metastatic variant MDA-231BO cells in suspension were examined for levels of phospho-MLC and total MLC by immunoblotting after treatment with or without $5 \mathrm{nM}$ IGF-I for $10 \mathrm{~min}$ with or without pretreatment of Y-27632 $(2 \mu \mathrm{M})$. Figure labeling: S-SFM; I-IGF; Y-Y27632. (c) MDA-231BO cell adhesion to fibronectin was examined in the presence and absence of $5 \mathrm{nM}$ IGF-I and Y-27632. The results were shown as O.D. reading at $570 \mathrm{~nm}$, which was proportional to the adherent cell number. (d) MDA-231BO cell motility was examined in the presence and absence of IGF-I $(5 \mathrm{nM})$ and $\mathrm{Y}-27632(2 \mu \mathrm{M})$ using the gold particle migration assay. The results are shown as percentage by using basal migration (without IGF-I and Y-27632) as a $100 \%$ control.

Thus, IGF1R activation of ROCK stimulates motility without influencing cell adhesion.

$M A P K, P I-3 K$, and $p 38$ activities are also required for IGF-I stimulated MDA-231BO cell migration

We and others have shown that IGF-I stimulates both MAPK and PI-3K in MCF-7 breast cancer cells to enhance growth [31,32]. To determine if these pathways are also involved in IGF-mediated cell migration, we pre-treated MDA-231BO cells with either PD98059 (MEK inhibitor) or wortmannin (PI3K inhibitor) prior to IGF-I exposure. We have previously shown that these chemicals inhibit IGF-stimulated cell proliferation [31]. Figure 5 shows that both compounds blocked the IGF-I stimulated cell migration. Immunoblotting results show that MDA-231BO cells have constitutively activated MAPK. PD98059 did not completely block the MAPK phosphorylation even at very high concentration (Figure 6a). In contrast, $75 \mathrm{nM}$ wortmannin inhibited IGF-I activation of Akt, a downstream target of PI3K (Figure 6b). These results suggested that MAPK and PI$3 \mathrm{~K}$ signaling pathways are required for IGF-I mediated cell migration. However, MAPK was not stimulated by IGF-I, suggesting that it was not a direct effector of IGF-I stimulated cell migration. In addition, since PI3K

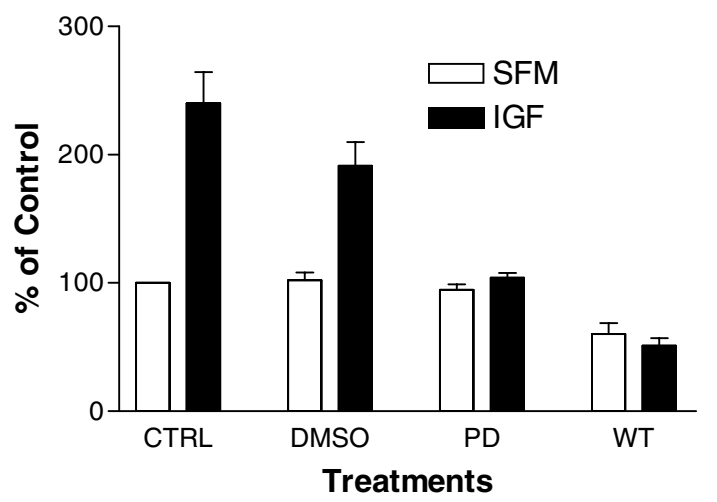

Figure 5. PI-3K and MAPK inhibitors blocked IGF-I stimulated MDA-231BO cell motility. MDA-231BO cells were treated with vehicle (DMSO), $25 \mu \mathrm{M}$ PD98059 (PD), $250 \mathrm{nM}$ wortmannin (WT) or no pre-treatment (CTRL) for 30 min prior to IGF-I treatment. Results are shown as percent of control (serum free media).

is activated by IGF-I in non-migrating cells this pathway may have a role in both mediating mitosis and motility.

Since p38 has been reported to be activated by small GTPases, we next examined if IGF-I could activate p38 phosphorylation. As shown in Figure 7a, IGF-I stimulated p38 phosphorylation in a time course similar to 
(a) $\mathrm{PD}(\mu \mathrm{M})$

Phospho-MAPK
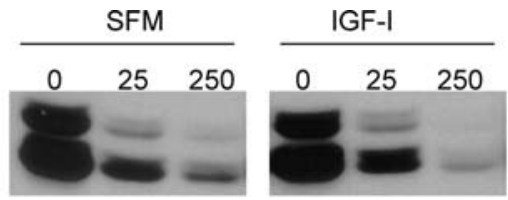

Total MAPK
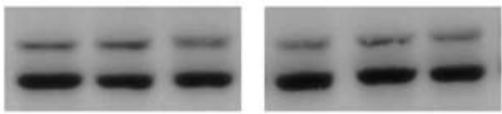

(b)

WT (nM)

SFM

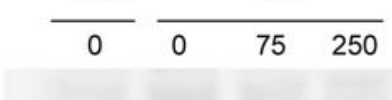

IGF

WT (nM)
Phospho-AKT

Total AKT

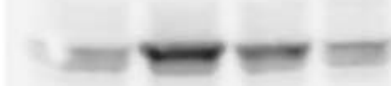

Figure 6. Effect of PD98059 and wortmannin on IGF-I mediated MAPK and PI-3K signaling. (a) MAPK activation was measured by phosphospecific antibodies (top panel) in the presence of increasing concentrations of PD98059. Phospho-MAPK was detected in unstimulated cells and IGF-I did not increase levels PD98059 inhibited MAPK signaling in samples treated with or without IGF-I. (b) AKT activation was measured by phosphospecific antibodies. 5 nM IGF-I stimulated AKT phosphorylation and this activation was inhibited by $250 \mathrm{nM}$ wortmanin.

RhoA activation (Figure 3a). ROCK inhibitor Y-27632 could partially block both basal and IGF-I stimulated p38 phosphorylation (Figure 7b). SB203580 specifically inhibits p38 at low concentrations $(4-20 \mu \mathrm{M})$ while higher concentrations also inhibit other kinases such as LCK, PKB $\alpha$, GSK $3 \beta$, c-Raf and JNK2 $\beta 1$. In these cells, low concentrations of SB203580 inhibited IGF-I effects while concentrations greater than $50 \mu \mathrm{M}$ also blocked basal cell migration (Figure 7c). Since both Y-27632 and
SB203580 inhibited IGF-I stimulated motility and p38 activation; these data suggest that p38 may be downstream of RhoA/ROCK.

\section{Discussion}

Cell migration is a dynamic process requiring the integration of multiple signaling pathways. Moving cells are constantly exposed to mechanical and chemical environmental cues [33]. Engagement of integrin receptors with their extracellular ligands leads to the formation of focal adhesion contacts, which links the ECM with the intracellular actin cytoskeleton. Thus, mechanical forces generated by the cell's own actin-myosin contractile machinery are activated by specific ECM proteins found in the extracellular environment. At same time, cells are receiving additional environmental signal, from molecules such as growth factors, via their own cognate cell surface receptors.

IGF-I initiates its biological effects by interacting with IGF1R, which then recruits and phosphorylates specific adaptor proteins including the IRS molecules. We have previously shown IRS-2 is involved in IGF-I mediated cell migration in MDA-231 breast cancer cells [2], but the exact function for IRS-2 in this process is not well defined. In this study, we further investigated IRS-2 subcellular localization after IGF-I exposure. We found that IGF-I causes IRS-2 to concentrate at the cell leading edge, which supports its role in sensing the environmental cues and directing cell movement.

FAK is a major kinase located at focal adhesion contacts and initiates the actin-myosin mechanical force upon appropriate integrin ligation. We have found that MDA-231BO cells have very low FAK activity (phosphorylation) in suspension. By allowing cellular attachment to attach to fibronectin coated plate (a)

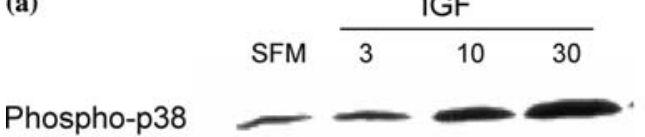

(b)

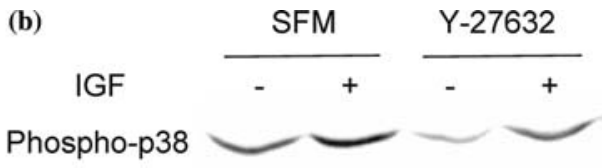

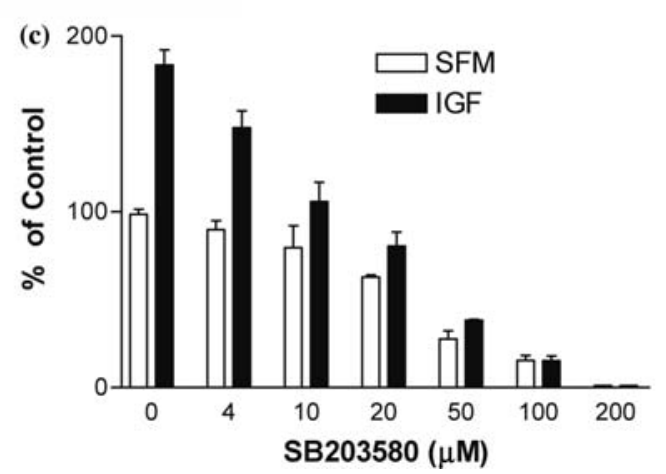

Figure 7. p38 inhibition inhibited IGF-I stimulated cell motility (a) Phosphospecific antibodies were used to measure activated p38. Cells were treated with $5 \mathrm{nM}$ IGF-I from 0-30 min. p38 was activated by IGF-I in a time course similar to that of RhoA. (b) ROCK inhibitor Y-27632 $(2 \mu \mathrm{M})$ partially inhibited p38 signaling in attached MDA-231BO cells with and without IGF-I treatment. (c) SB203580 (4-200 $\mu$ M) inhibited both basal and IGF-I stimulated cell migration in a dose-dependent manner in MDA-231BO cells. 
for 10 min, FAK is highly activated and IGF-I has no effect on FAK activity either in suspended or attached cells. In accordance with the report that IGF-I induces dephosphorylation of FAK in MCF-7 breast cancer cells [34], we found that FAK gradually disappeared from focal adhesion sites after IGF-I treatment. These results suggest that in MDA-231BO breast cancer cells, FAK activation is mainly regulated by integrin ligation while IGF-I downregulates FAK activity by diminishing its presence at the focal adhesion contacts. Recent report suggests that Src family kinases are essential for the phosphorylation-dependent exclusion of FAK from focal adhesions [35]. Thus, tyrosine kinase activity initiated by IGF-I may enhance cell movement by diminishing focal adhesions. Recently, Lynch et al. have shown that IGF-I decreases adhesion strength of MCF-7 cells transfected with IGF1R [36]. These authors find that the IGF-mediate effects of adhesion strength are independent of ROCK activation, but are dependent on IGF1R signaling to PI-3K. While these cells express supraphysiologic levels of IGF1R, the results support the idea that complex signaling initiated by this receptor can mediate several aspects of breast cancer cell motility.

The mechanical properties of the cell are largely regulated by cytoskeletal architecture of microfilaments, intermediate filaments (IF), and microtubules. Vimentin belongs to the IF network and little is known about its function in migrating cells. Recently, it has been reported that the rigidity of circulating lymphocytes is primarily conferred by vimentin and their regulated collapse is likely to be an essential element in chemokine-induced transendothelial migration [18]. Overexpression of RhoA or growth factor treatment is associated with disassembly of vimentin IFs in fibroblasts and rat mesangial cells $[19,37]$. In this study, we also found that before IGF-I treatment, MDA-231BO cells contain a perinuclear ring of vimentin. During IGF-mediated cell migration, the vimentin ring loosened and became dissembled. The collapse of vimentin network may be necessary to achieve the increased cell deformability required for IGF-I mediated cell migration. It has been reported that vimentin phosphorylated by ROCK also loses its ability to form filaments in vitro [38].

Rho family GTPases control cell adhesion and motility through reorganization of the actin cytoskeleton and regulation of actomyosin contractility [39]. In this study, we failed to detect Rho activation in attached cells after IGF-I treatment for as long as $30 \mathrm{~min}$. However, with cells in suspension, IGF-I rapidly stimulated RhoA activation within $1 \mathrm{~min}$. GTP-bound RhoB was decreased after IGF-I treatment. IGF-I did not change levels of GTP-bound RhoC, RhoG or cde 42 . Our findings suggest that IGF-I activation of RhoA may have a very important role in detached cells, as would be found in circulating tumor cells. It is clear that a significant number of 'early stage' breast cancer patients have circulating tumor cells [40]. While the presence of these cells is a poor prognostic factor, it is also clear that many women with circulating tumor cells do not suffer clinical disease recurrence. It is possible that additional growth factor-mediated signaling events are necessary for circulating tumor cells to display their full metastatic potential.

In further study of RhoA activation by IGF-I, we found that ROCK inhibitor Y-27632 effectively inhibited IGF-I mediated cell migration in MDA-231BO cells. The fact that IGF-I stimulated cell adhesion was not affected by ROCK inhibitor indicates other signaling pathway, other than Rho, may be required for IGF-stimulated adhesion. During migration, cell body contraction depends on phosphorylation of actomyosin. ROCK inhibits MLC phosphatase allowing enhanced activity of MLC. We show that MLC phosphorylation is induced by IGF-I and, as expected, inhibition of ROCK inhibits IGF-mediated cell motility. RhoROCK-MLC signaling pathway is involved in IGF-I stimulated cell motility in metastatic breast cancer cells.

p38-MAPK has been reported to be activated either by cdc42/Rac/PAK/MKK3/6 mediated pathway $[16,41]$ or by Rho/ROCK signaling [14]. In MDA-231BO cells, IGF-I did not affect Rac and cdc42 activity. On the other hand, IGF-I stimulated p38 phosphorylation in a manner similar to RhoA activation. Furthermore, ROCK inhibitor Y-27632 diminished both basal and IGF-I stimulated p38 activity. These data suggest that p38 is downstream of RhoA/ROCK in MDA-231BO breast cancer cells.

Erk and PI-3K signaling pathways are well studied and play important roles in almost every aspect of cancer cell biology. We have also shown previously that both pathways are required in IGF-mediated growth in MCF-7 cells [31]. In MDA-231BO cells, monolayer growth is not stimulated by IGF-I (data not shown). MDA-231BO cells have constitutively activated Erk 1 and Erk2 and no further stimulation was evident after IGF-I treatment. In contrast, Akt was activated by IGF-I in these cells. Inhibition of Erk and PI-3K inhibited IGF-I mediated cell migration, suggesting both pathways are necessary for this phenotype. Activation of MAPK appears to be a required pathway for motility but does not appear to be downstream of IGF action in these cells.

In summary, IGF-I mediated MDA-231BO breast cancer cell migration requires coordination of multiple signaling pathways. Some of the pathways are independent of IGF-I action, such as MAPK, but others (RhoA/ROCK/MLC) appear directly activated by IGF-I. In addition, coordinated signaling through integrin receptors is also necessary for IGF-I stimulated motility. Our data suggest that the metastatic phenotype is potentially vulnerable to inhibition of IGF signaling. Moreover, optimal inhibition of the metastatic phenotype may require blockade of several molecules, either in series or in parallel. Since many of the appropriate inhibitors are now being tested in clinical trial, the complexity of the contributions of multiple signaling components to metastasis needs to be considered to design the most effective cancer therapies. 


\section{Acknowledgements}

This work was supported by NIH Grant R01 CA74285 and PHS Cancer Center Support Grant P30 CA77398.

\section{References}

1. Doerr ME, Jones JI: The roles of integrins, extracellular matrix proteins in the insulin-like growth factor I-stimulated chemotaxis of human breast cancer cells. J Biol Chem 271: 2443-2447, 1996

2. Jackson JG, Zhang X, Yoneda T, Yee D: Regulation of breast cancer cell motility by insulin receptor substrate-2 (IRS-2) in metastatic variants of human breast cancer cell lines. Oncogene 20: 7318-7325, 2001

3. Sahai E, Marshall CJ: RHO-GTPases and cancer. Nat Rev Cancer 2: $133-142,2002$

4. Jaffer ZM, Chernoff J: The cross-Rho'ds of cell-cell adhesion. J Biol Chem 279: 35123-35126, 2004

5. Fritz G, Brachetti C, Bahlmann F, Schmidt M, Kaina B: Rho GTPases in human breast tumours: expression and mutation analyses and correlation with clinical parameters. Br J Cancer 87: 635-644, 2002

6. Ahn SJ, Chung KW, Lee RA, Park IA, Lee SH, Park DE, Noh DY: Overexpression of betaPix-a in human breast cancer tissues. Cancer Lett 193: 99-107, 2003

7. Schnelzer A, Prechtel D, Knaus U, Dehne K, Gerhard M, Graeff H, Harbeck N, Schmitt M, Lengyel E.: Racl in human breast cancer: overexpression, mutation analysis, and characterization of a new isoform, Rac1b. Oncogene 19: 3013-3020, 2000

8. van Golen KL, Wu ZF, Qiao XT, Bao LW, Merajver SD: RhoC GTPase, a novel transforming oncogene for human mammary epithelial cells that partially recapitulates the inflammatory breast cancer phenotype. Cancer Res 60: 5832-5838, 2000

9. Kleer CG, Golen KLvan, Zhang Y, Wu ZF, Rubin MA, Merajver $\mathrm{SD}$ : Characterization of RhoC expression in benign and malignant breast disease: a potential new marker for small breast carcinomas with metastatic ability. Am J Pathol 160: 579-584, 2002

10. Bouzahzah B, Albanese C, Ahmed F, Pixley F, Lisanti MP, Segall JD, Condeelis J, Joyce D, Minden A, Der CJ, Chan A, Symons M, Pestell RG.: Rho family GTPases regulate mammary epithelium cell growth and metastasis through distinguishable pathways. Mol Med 7: 816-830, 2001

11. Kimura K, Ito M, Amano M, Chihara K, Fukata Y, Nakafuku M, Yamamori B, Feng J, Nakano T, Okawa K, Iwamatsu A, Kaibuchi K: Regulation of myosin phosphatase by Rho and Rhoassociated kinase (Rho-kinase). Science 273: 245-248, 1996

12. Maekawa $M$, Ishizaki $T$, Boku $S$, Watanabe $N$, Fujita A, Iwamatsu A, Obinata T, Ohashi K, Mizuno K, Narumiya S: Signaling from Rho to the actin cytoskeleton through protein kinases ROCK and LIM-kinase. Science 285: 895-898, 1999

13. Yoshioka K, Foletta V, Bernard O, Itoh K: A role for LIM kinase in cancer invasion. Proc Natl Acad Sci USA 100: 7247-7252, 2003

14. Ashida N, Arai H, Yamasaki M, Kita T: Distinct signaling pathways for MCP-1-dependent integrin activation and chemotaxis. J Biol Chem 276: 16555-16560, 2001

15. Zhang S, Han J, Sells MA, Chernoff J, Knaus UG, Ulevitch RJ Bokoch GM: Rho family GTPases regulate p38 mitogen-activated protein kinase through the downstream mediator Pak1. J Biol Chem 270: 23934-23936, 1995

16. Bagrodia S, Derijard B, Davis RJ, Cerione RA: Cdc42 and PAKmediated signaling leads to Jun kinase and p38 mitogen- activated protein kinase activation. J Biol Chem 270: 27995-27998, 1995

17. Brahmbhatt AA, Klemke RL: ERK and RhoA differentially regulate pseudopodia growth and retraction during chemotaxis. J Biol Chem 278: 13016-13025, 2003

18. Brown MJ, Hallam JA, Colucci-Guyon E, Shaw S: Rigidity of circulating lymphocytes is primarily conferred by vimentin intermediate filaments. J Immunol 166: 6640-6646, 2001
19. Sin WC, Chen XQ, Leung T, Lim L: RhoA-binding kinase alpha translocation is facilitated by the collapse of the vimentin intermediate filament network. Mol Cell Biol 18: 6325-6339, 1998

20. Sachdev P, Jiang YX, Li W, Miki T, Maruta H, Nur EKMS, Wang LH: Differential requirement for Rho family GTPases in an oncogenic insulin-like growth factor-I receptor-induced cell transformation. J Biol Chem 276: 26461-26471, 2001

21. Cheng HL, Steinway ML, Russell JW, Feldman EL: GTPases and phosphatidylinositol 3-kinase are critical for insulin-like growth factor-I-mediated Schwann cell motility. J Biol Chem 275: $27197-$ 27204, 2000

22. Zhang $\mathrm{X}$, Yee $\mathrm{D}$ : Insulin-like growth factor binding protein-1 (IGFBP-1) inhibits breast cancer cell motility. Cancer Res 62: 4369-4375, 2002

23. Yoneda T, Williams PJ, Hiraga T, Niewolna M, Nishimura R: A bone-seeking clone exhibits different biological properties from the MDA-MB-231 parental human breast cancer cells and a brainseeking clone in vivo and in vitro. J Bone Miner Res 16: 14861495, 2001

24. Ratcliffe MJ, Smales C, Staddon JM: Dephosphorylation of the catenins p120 and p100 in endothelial cells in response to inflammatory stimuli. Biochem J 338: 471-478, 1999

25. Sander EE, ten Klooster JP, van Delft S, van der Kammen RA, Collard JG: Rac downregulates Rho activity: reciprocal balance between both GTPases determines cellular morphology and migratory behavior. J Cell Biol 147: 1009-1022, 1999

26. van Golen KL, Bao LW, Pan Q, Miller FR, Wu ZF, Merajver SD: Mitogen activated protein kinase pathway is involved in RhoC GTPase induced motility, invasion and angiogenesis in inflammatory breast cancer. Clin Exp Metastasis 19: 301-311, 2002

27. Albrecht-Buehler G.: The phagokinetic tracks of 3 T3 cells. Cell 11: 395-404, 1977

28. Meyer GE, Shelden E, Kim B, Feldman EL: Insulin-like growth factor I stimulates motility in human neuroblastoma cells. Oncogene 20: 7542-7550, 2001

29. Zhang X, Kamaraju S, Hakuno F, Kabuta T, Takahashi S, Sachdev D, Yee D: Motility response to insulin-like growth factorI (IGF-I) in MCF-7 cells is associated with IRS-2 activation and integrin expression. Breast Cancer Res Treat 83: 161-170, 2004

30. Maekawa M, Ishizaki T, Boku S, Watanabe N, Fujita A, Iwamatsu A, Obinata T, Ohashi K, Mizuno K, Narumiya S: Signaling from Rho to the actin cytoskeleton through protein kinases ROCK and LIM-kinase. Science 285: 895-898, 1999

31. Jackson JG, White MF, Yee D.: Insulin receptor substrate-1 is the predominant signaling molecule activated by insulin-like growth factor-I, insulin, and interleukin-4 in estrogen receptor-positive human breast cancer cells. J Biol Chem 273: 9994-10003, 1998

32. Dufourny B, Alblas J, Teeffelen HAvan, van Schaik FM, van der Burg B, Steenbergh PH, Sussenbach JS: Mitogenic signaling of insulin-like growth factor I in MCF-7 human breast cancer cells requires phosphatidylinositol 3-kinase and is independent of mitogen-activated protein kinase. J Biol Chem 272: 31163-31171, 1997

33. Geiger B, Bershadsky A: Exploring the neighborhood: adhesioncoupled cell mechanosensors. Cell 110: 139-142, 2002

34. Guvakova MA, Surmacz E: The activated insulin-like growth factor I receptor induces depolarization in breast epithelial cells characterized by actin filament disassembly and tyrosine dephosphorylation of FAK, Cas, and paxillin. Exp Cell Res 251: 244-255, 1999

35. Katz BZ, Romer L, Miyamoto S, Volberg T, Matsumoto K, Cukierman E, Gieger B, Yamada KM: Targeting membranelocalized FAK to focal adhesions: Roles of tyrosine phosphorylation and Src family kinases. J Biol Chem 16:-16, 2003

36. Lynch L, Vodyanik PI, Boettiger D, Guvakova MA: Insulin-like growth factor I controls adhesion strength mediated by alpha5beta 1 integrins in motile carcinoma cells. Mol Biol Cell 16: 51-63, 2005

37. Berfield AK, Raugi GJ, Abrass CK: Insulin induces rapid and specific rearrangement of the cytoskeleton of rat mesangial cells in vitro. J Histochem Cytochem 44: 91-101, 1996

38. Goto H, Kosako H, Tanabe K, Yanagida M, Sakurai M, Amano M, Kaibuchi K, Inagaki M: Phosphorylation of vimentin by 
Rho-associated kinase at a unique amino-terminal site that is specifically phosphorylated during cytokinesis. J Biol Chem 273: 11728-11736, 1998

39. Etienne-Manneville S, Hall A: Rho GTPases in cell biology. Nature 420: 629-635, 2002

40. Stathopoulou A, Vlachonikolis I, Mavroudis D, Perraki M, Kouroussis C, Apostolaki S, Malamos N, Kakolyris S, Kotsakis A, Xenidis N, Reppa D, Georgoulias V: Molecular detection of cytokeratin-19-positive cells in the peripheral blood of patients with operable breast cancer: evaluation of their prognostic significance. J Clin Oncol 20: 3404-3412, 2002
41. Lee SH, Eom M, Lee SJ, Kim S, Park HJ, Park D: BetaPixenhanced p38 activation by $\mathrm{Cdc} 42 / \mathrm{Rac} / \mathrm{PAK} / \mathrm{MKK} 3 / 6$-mediated pathway. Implication in the regulation of membrane ruffling. J Biol Chem 276: 25066-25072, 2001

Address for offprints and correspondence: Douglas Yee, Department of Medicine, University of Minnesota Cancer Center, Minneapolis, MN, 55455, USA; Tel: +1-612-626-8487; Fax: +1-612-626-4842; E-mail: yeexx006@umn.edu 